\title{
AGUA MALGASTADA Y AGUA UTILIZADA. OBSERVACIONES SOBRE LA MODERNIZACIÓN DEL REGADÍO EN EL OASIS DE KUQAR (XINJIANG, REPÚBLICA POPULAR CHINA) ${ }^{1}$
}

\author{
P. Faggi*
}

En el marco de una sólida e invasora política de colonización de las tierras secas, desde 1949, la República Popular China ha activado procesos de transformación profunda en la Región Occidental de Xinjiang (Gentelle, 1974; Betke y Küchler, 1986; Faggi, 1988).

Dicha colonización ha sido abordada con objetivos múltiples: productivos, dada la enorme demanda de recursos necesarios para un proyecto estatal de dimensiones ilimitadas (por lo que se refiere a los recursos alimenticios, cfr. Gruschke, 1974); estratégicos, dado que en estas lejanas tierras fornterizas los límites son delicadísimos y existen minorías étnicas tradicionalmente hostiles a Pekín animadas por tendencias separatistas ${ }^{2}$. Es un proyecto general de integración que implica a parte del Estado, que intenta activar procesos territoriales dirigidos al propio desarrollo de la región. Se trata de una estrategia rica e integrada por muchos medios de actuación y prácticas territoriales diversificadas que, no obstante, tienen en la gestión de recursos hídricos la clave de su éxito.

Como instrumento decisivo para el control y revaloración de las tierras secas, la gestión de recursos hídricos, asume un indiscutible valor estratégico en la ordenación territorial en un ámbito árido. Esta afirmación, que puede resultar banal en su validez general, adquiere significados específicos y muy fuertes en el caso de estados, como sucede en el chino, que

* Profesor de la Universidad de Padua (texto traducido por Gloria Navarro Albaladejo y revisado por Juan Antonio Marco Molina).

1 Esta investigación ha sido financiada al 60\% por el Ministerio Universitario de Investigación Científica y Técnica y por el Centro Nacional de Investigación de Italia. En el ámbito de este programa de estudio —-todavía en curso - se han llevado a cabo visitas a la cuenca del Tarim en 1985, 1989, 1990 y 1991, en colaboración con el Instituto de Geografía de Xinjiang, de la Academia Sinica, en Ürümqui. En particular, el Oasis de Kuqar ha sido objeto de una investigación en colaboración con los colegas Xie Xiang-Fang, Mao Baodi, Heret y Thomas Hoppe, en mayo-junio de 1989, entonces todos investigadores en la Technischen Universität de Berlín, Fachbereich Landschaftsentwicklung.

A estos colegas, a todos los funcionarios, a los miembros de los gobiernos locales, y a los habitantes del Oasis de Kuqar, quiero expresar mi más sentido agradecimiento.

2 Para la cuestión de las relaciones entre Han y poblaciones turcas en Asia Central, consúltese, en general, Lattimore, 1970; Benson y Svanberg, 1988; Cagnat y Jan, 1981. Para consultar los datos más recientes, véase Cannon, 1989, y con buena documentación estadística, Hoppe, 1992. La compleja percepción del mundo uighur actual, por parte de los Han viene contemplada en Gladney, 1992. 
buscan márgenes más amplios para la propia reproducción a través de procesos de colonización interna de tierras secas. Estados que, para aumentar los recursos disponibles del propio proyecto, intervienen en espacios áridos transformando sus dinámicas territoriales.

En esta construcción, de marcadas connotaciones geográficas, la práctica hidráulica tiene un papel decisivo, por cuanto sobre ella se articula la relación entre proyecto estatal y estructuras territoriales precedentes. Mediante la nueva gestión de las aguas, se pretende la reorganización productiva, la transformación social y el control del espacio: una gestión diferente del agua significa un nuevo desarrollo del territorio. Es más, la nueva proyección no se explica en el vacío. En torno a la gestión de las aguas se articulan conflictividad y adecuación entre el antiguo y el nuevo sistema territorial, de la nueva gestión del agua se deriva el surgimiento de problemas inéditos hasta la fecha o el agravamiento de otros ya existentes, y, por tanto, la elaboración de una nueva respuesta social. En torno al agua se enfrentan y confrontan estrategias territoriales diferentes en el mismo espacio físico, diseñando su nueva geografía.

Las recientes transformaciones en el oasis de $\mathrm{Kuqar}^{3}$ situado en el piedemonte meridional del Tian Shan, pueden observarse desde esta perspectiva, como una transformación de las relaciones entre agua, sociedad y territorio.

\section{Los componentes naturales de la construcción territorial}

El Oasis de Kuqar se extiende sobre un amplio abanico en la parte central del piedemonte meridional del Tian Shan, la gran cadena del norte de la cuenca del Tarim (fig. 1.a.). El cono formado por la coalescencia de detritos de los ríos Kuqar y Ögän (en chino, Weigan) desciende desde los $1.100 \mathrm{~m}$ de altitud hasta los $960 \mathrm{~m}$ de la llanura aluvial del Tarim. La pendiente, que disminuye progresivamente desde $0{ }^{\prime} 4-0$ ' $5 \%$ en el vértice del abanico a valores inferiores a 0 ' $1 \%$ en la parte distal del mismo, resulta, en general, mayor en la parte oriental, formada por sedimentos del Kuqar, dotado de menor capacidad de trasporte que el Ögän.

En sentido transversal, además de esta disimetría general, el cono se articula en una serie de digitaciones divergentes y elevadas sobre el llano del vértice, formadas por depósitos de los numerosos y cambiantes cauces; los cuales, alternándose con las depresiones colaterales originan un microrrelieve de algunos metros (fig. 2).

Separando el oasis de la cadena principal del Tian Shan, que lo cierra con una muralla compacta hacia Zungaria y el valle de $\mathrm{Ili}^{4}$, se encuentran las alineaciones de relieves de piedemonte de los Qöl Tagh. Sus formaciones, poco coherentes, acabaron de acumularse cuando ya el levantamiento cenozoico de las grandes cadenas mantenía a la cuenca aislada de la circulación de las masas de aire húmedo, confiriéndole un elevado grado de aridez y un régimen endorreico (Meckelein, 1986). Son, por lo tanto, formaciones ricas en sales

3 Además de la transcripción Kuqar, se encuentran Kuqa y Kucha; la transcripción pinyin que responde a la pronunciación china es Kuche. En la región existe, obviamente, la doble toponimia: donde es posible, aquí ha sido adoptada la turca. Por lo que se refiere a la organización administrativa del oasis, incluido en la prefectura (Diqu) de Aksu, se divide en los distritos (Xian) de Kuqar, Toksu (en chino Xinhe) y Xayar, cada uno repartido en cantones rurales (Xiang, antiguo pueblo popular rural: 13 en Kuqar, 6 en Toksu, 7 en Xayar) y en ciudades (una para Xian). Figura $1 \mathrm{c}$; para un cuidado, aunque fechado tratamiento de la estructura territorial de la administración; cfr. Trolliet, 1981:26.

4 Tradicionalmente, el acceso en esa dirección se efectuaba a través del inaccesible paso Muzart (3.620 metros sobre el nivel del mar), en la cabecera del río homónimo, o por un largo recorrido que pasa por Korla, las puertas de hierro y Ürünqui (Scomberg, 1930 b). 
Figura 1. El Oasis de Kuqar. a) 1: $>4.000 \mathrm{~m}$ de altitud. 2: >2.000 m de altitud. 3: desierto costero. 4: río y oasis. 5: límites de Estado y provinciales. b) 1: $>1.500 \mathrm{~m}$ de altitud. 2: arenas. 3: Tokay. 4: área cultivada. 5: río, canal, embalse. 6: pantano. 7: sección de fig. 2. 8: profundidad del nivel freático ants de la colonización/hoy. c) 1: >1.500 altitud. 2: carretera principal, secundaria, límites de Xian. 4: cabecera de Xian, otro centro. 5: nuevo centro de asentamiento en el Tokay. 
(carbonatos, fosfatos, cloruros) y aportan a los ríos una elevada proporción salina que se transmite también a la capa freática. Entre la cadena principal y los relieves de piedemonte se encuentra la cuenca intramontana de Benqeng, con cotas comprendidas entre $1.200 \mathrm{y}$ $1.400 \mathrm{~m}$ de altitud, circundada por montañas fuertemente erosionadas.

Hacia el valle, el oasis, desaparece en la llanura aluvial del Tarim, a la cual el desarrollo del cono reduce hasta un mínimo de una treintena de kilómetros; más allá del río, comienzan los médanos y dunas longitudinales del Takla Makan, intercaladas hacia el sur con antiguos cauces secos ${ }^{5}$.

El clima de Kuqar, al igual que toda la cuenca del Tarim, se caracteriza por su extrema continentalidad, acentuada por la estructura orográfica regional (Petrov, 1962), y es de tipo hiperárido, con inviernos fríos (temperatura media invernal inferior a $0^{\circ} \mathrm{C}$ ), y veranos cálidos (con temperaturas entre 20 y $30^{\circ} \mathrm{C}$ ) (Unesco, 1977). Las temperaturas registran fortísimas amplitudes, con medias estivales próximas a $25^{\circ} \mathrm{C}$ e invernales inferiores a $-10^{\circ} \mathrm{C}$ (pero con extremas batante frecuentes de $40^{\circ}$ y $-20^{\circ} \mathrm{C}$ respectivamente). Son recurrentes las inversiones térmicas, tanto en la cuenca intramontana, como en la parte baja del abanico aluvial, que pueden llevar a episodios de heladas precoces o tardías. Precisamente por este motivo, el calor anual acumulado $\left(\mathrm{T}>10^{\circ}\right)$ que supera los $4.200^{\circ}$ en el piedemonte, desciende en la llanura a $3.950^{\circ}$, mientras que los períodos libres de heladas son de 218 y 180 días respectivamente.

En la estación invernal, el anticiclón ruso-siberiano instaura en la cuenca aire seco a temperaturas bajísimas, con fuertes vientos septentrionales que se canalizan en descenso desde los altos valles del Tian Shan (fuerza 6-7); a ellos se asocian frecuentes tempestades de polvo (kara buran) y, por recalentamiento adiabático, vientos cálidos y desecantes, sobre todo en el inicio de la primavera. En dicha estación y durante el verano las masas de aire húmedo provinientes del noroeste, sur y este, llegan a la cuenca ya desecadas por haber descargado en las vertientes de barlovento de las grandes cadenas centroasiáticas y, si bien aumentan la humedad y la nubosidad de la región, sólo reportan algún aguacero esporádico. En la primavera tardía, son frecuentes, en toda la zona de piedemonte, fuertes granizadas. Las escasísimas lluvias asociadas sobre todo a la advección occidental - de $150 \mathrm{~mm} /$ año en los Qöl Tagh a menos de $50 \mathrm{~mm}$ en la sección inferior del cono- (fig. 3) deben afrontar una ETP de más de 2.500 mm/año.

Obviamente, la situación es distinta para la cadena del Tian Shan, que, como las grandes cadenas centroasiáticas, representa una isla de humedad en el centro de un mar árido. En altitud aumentan las precipitaciones, superando los $600 \mathrm{~mm}$ anuales en las cimas, a más de $3.500 \mathrm{~m}$ de altitud, y según la exposición, una considerable cobertera glacial interesa la parte más elevada de las vertientes ${ }^{6}$.

Del Tian Shan descienden los ríos que alimentan el oasis, el Kuqar y el Ögän. Ambos, de régiman nivo-glacial en cabecera, registran fuertes variaciones estacionales de su caudal, con crecida tardoestival y escasez invernal y primaveral, pero débil variabilidad

5 En la sección central de su llanura aluvial, extremadamente plana (pendiente longitudinal de 0,03\%) el Tarim, dotado de una elevada capacidad de carga sólida, ha desarrollado una serie enorme de cursos anastomosados y de divagaciones laterales, que eran retomadas o abandonadas en los rebordes ligados a las crecidas; si la disminución de la capacidad debida a la expansión del regadío ha conducido a su desactivación en la zona occidental, las mismas forman aún un fantástico laberinto anfibio en el valle del Oasis de Kuqar.

6 El Tian Shan es la cadena generalmente más rica de masas glaciales de todo el Xinjiang: 8.908 glaciares de $9.196 \mathrm{~km}^{2}$ de extensión y $1.010 \mathrm{~km}^{3}$ (sobre un total regional de $28.784 \mathrm{~km}^{2}$ y de $2.894,75 \mathrm{~km}^{3}$ ) (Shi Yafeng et alii, 1989). Particularmente rica resulta la parte central de la cadena, en torno al Tomur Tengri y al Han Tengri, que superan los $7.000 \mathrm{~m}$ sobre el nivel del mar. 
FIGURA 2. El microrrelieve y la utilización del suelo en Kuqar (para la localización, cfr. fig. 1.b). a: bagh baran tradicional. b: otlak (pastizal salino). c: maydan en expansión, con nuevos asentamientos. d: bagh baran en transformación a campo abiertos.

Fuente: T. Hoppe, 1992, modificado.

FiguRa 3. Diagrama ombrotérmico de Kuqar.

FUENTE: UNESCO, 1977.

interanual (fig. 4) ${ }^{7}$. El Ögän que tiene su origen en la región de los principales glaciares del Han Tengri y que avena el vasto sector en el norte de la cuenca de Benqeng, ve su caudal invernal sostenido en cierto modo (cfr. los porcentajes invernales) por los flujos subsuperficiales que se activan en las potentes capas aluviales de la misma cuenca: es un hecho frecuente en el Tian Shan (Zhou Yuchao, 1989; Betke, Küchen y Obenauf, 1987) que explica la limitadísima variabilidad de los volúmenes invernales y que señala una clara diferencia con el Kuqar, en el cual la falta de estos aportes invernales hace registrar una cota en los meses fríos aún más exigua. El empobrecimiento progresivo de este flujo, y de las también irrisorias precipitaciones de fines de invierno, lleva al mínimo absoluto de abril y mayo: en este último mes pueden verificarse chubascos y deshielos precoces, con una variabilidad que crece repentinamente y que, como veremos, añade a la escasez del agua

7 La elaboración se refiere al período 1956-87 con la falta de algunos datos, sobre todo, durante El Gran Salto y la Revolución Cultural. 
FIGURA 4. Los volúmenes del Ögän y su variabilidad.

FuENTE: Elaboración sobre datos de la Autoridad del Ögän.

un ulterior elemento de inseguridad y de agitación en las operaciones agrícolas. Las crecidas estivales determinan una elevada variabilidad, lo que les puede hacer asumir visos catastróficos. Un elevado transporte sólido, alimentado por las formaciones incoherentes de los Qöl Tagh, caracteriza a los dos cursos de agua, formando vastos lechos de inundación en la parte septentrional de oasis y alveos colgados en la parte meridional ${ }^{8}$.

La catena de suelos presenta la secuencia normal de las zonas áridas: en la cuenca intramontana y en la proción superior del cono, suelos pardos desérticos (en chino zongmo-tu), que tienden a empobrecerse progresivamente en la parte inferior, donde aparecen los suelos grises (sierozem o hui-mo-tu). El abanico se compone de suelos aluviales, más o menos evolucionados en relación con el drenaje: en las depresiones, suelos hidromorfos de tipología varia (de pantano, de pradera cao-dian-tu), los cuales se asocian en las partes periféricas, en los extremos actuales o restos del drenaje, suelos salinos de diferente tipo (en chino, yan-tu); sobre los terrenos levantados de las digitaciones, encontramos suelos de

8 El Kizil Su, de nombre emblemático Río Rojo, puede llegar a una turbidez específica de $30 \mathrm{~kg} / \mathrm{m}^{3}$. En las compuertas de Kum Tura que reparten el agua del Ögän entre varios canales primarios del oasis (cfr. nota 42) se ha dado una sedimentación de 3 m en 20 años, parcialmente reanudada con ocasión de crecidas superiores a 3.000 $\mathrm{m}^{3} / \mathrm{s}$, como media cada 3 años. 
origen antrópico («suelos de oasis»: luzhou-tu), ligados a siglos de regadío y de fertilización, sobre matrices de suelos pardos y de suelos aluviales. En las vertientes de enlace, entre estos microrrelieves y las depresiones se dan suelos ligeros, compuestos por elementos orgánicos en un porcentaje cercano a la mitad (chao-tu).

La vegetación resulta bastante rala y fuertemente xerófila en terrenos elevados: en las partes medio-altas de las vertientes hasta $2.800 \mathrm{~m}$ de altitud, el predominio correspnde a la estepa semidesértica (Caragana, Nitraria, Artemisia sp. etc.), salvo un leve rastro de Picea schrenkiana en torno a los $2.500 \mathrm{~m}$ de altitud. Sobre secciones llanas, con suelos salinos y capas freáticas poco profundas, reposan sin embargo, coberteras arbustivas halófilas más espesas (Tamarix ramosissima, Kaldium, Salsola, Halinmodendion) o praderas palustres con Phragmites. De todas formas, la formación más rica e interesante es la de Populus diversifolia, P. pruinosa, Ulmus pumila, Elaeagnus sp. que, asociadas a la Glycyrrhiza glabra y a plantas halófilas, representan la esencia fundamental del tokay, el bosque de ribera del lecho de inundación del Tarim (Petrov, 1962).

Un ambiente áspero y difícil en el que incluso los recursos existentes están sometidos a márgenes de riesgo que funcionan como obstáculos graves. Radiación solar intensa y elevado calor acumulado a lo largo del año que, sin embargo, se corresponden con la aridez, bajísimas temperaturas invernales, riesgo de heladas tempranas y tardías, recurrencia de granizos y tempestades de polvo. Disponibilidades hídricas abundantes y seguras, pero fuertemente variables a lo largo del año, con una acusada escasez primaveral. Suelos de buena mezcla, sobre todo en las franjas elevadas, pero con la amenaza siempre presente de la sal. Un microrrelieve que favorece la infiltración, pero que es gravosa a cualquier hipótesis de colonización de las áreas deprimidas sometidas a un encharcamiento que se generaliza en el fondo del cono, hacia el lecho aluvial del Tarim.

\section{El regadío en el territorio tradicional}

«Au delà d'Ak son, toutes les autres villes du Turkestan chinois, Bai, Sairam, Koutcha, Chahyar, Bougour, Korla [......] Karachar, (las ciudades del piedemonte meridional del Tian Shan) sont éloignées du Tarim, qui coule à plus de 100 kilomètres au sud des contreforts du Tian Chan, en plein désert. Elles se sont élevées natuarallement à l'issue des vallées, où les eaux claires des torrents peuvent etre aisément conduites au milieu des jardins par les rigoles d'irrigation».

Así, con la base de los informes de viaje de A. N. Kuropatkin, que en 1876 había recorrido la margen septentrional de la cuenca del Tarim, resume E. Réclus (1882) en su Géographie Universelle, con una síntesis eficaz, la esencia de la relación de los asentamientos con los recursos hídricos. Una relación que se incardinaba sobre dos puntos básicos: la captación de aguas en el ápice del cono para utilizarlas con prioridad y seguridad aprovechando la altura relativa con respecto a los cultivos ${ }^{9}$; la repulsividad para el asentamiento urbano, pero también rural de la llanura aluvial, amenazada por salinidad

9 La necesidad de tener una adecuada altura de agua para poder regar las terrazas más elevadas (Schomberg, 1930 a:318) y el derecho del ribereño aguas arriba, parecen explicar el retranqueamiento de los oasis hacia la montaña, problema a propósito del cual la cuenca del Tarim es objeto, desde hace cerca de un siglo, de apasionadas discusiones. A lo largo de los módulos hidráulicos de la región existía una fuerte connotación montevalle, como se deduce de las observaciones de S. Hedin (1.900: 21) relativas a Khotan: secuencia según la corriente de distribución de agua primaveral y la posibilidad de fallo de cultivos para las porciones terminales de los canales. 
Figura 5. El oasis de Kuqar en los inicios del siglo.

e inundaciones.

El regadío tradicional asociado a este modelo territorial es del tipo de «derivación por gravedad», propia de gran parte de las formas de riego de piedemontes (Durand-Dastes, 1977:40): el agua de los ríos Kuqar y Ögän era —y es por lo que permanece del viejo modelo- distribuida por medio de grandes canales (östäng) que se dividían desde el ápice del cono (fig. 5). Los propios ríos funcionaban como canales de primer orden, con sus diversos ramales, conduciendo, con las divagaciones acaecidas a lo largo de la historia, el riego y la ocupación de diversos sectores del cono $^{10}$. La distribución del agua, ligada sobre todo a la altura de las crecidas, resultaba aún así, objeto de cierto control humano. En particular por lo que se refiere al Ögän, pues ya en 1896, existía un obstáculo en la agüera — salida del agua libre - del piedemonte, para controlar la bifurcación de los dos grandes ramales del río (Muzart y Shahiar de la figura 5) (Hedin, 1900: 58). Durante el estiaje, el

10 De ello son testimonio las ruinas de numerosos asentamientos, incluso de dimensiones considerables, dispuestos fuera de la actual zona regada. 
agua se concentraba en el ramal meridional, para descender y regar el sector homónimo, situado en la terraza aluvial entre el curso del Ögän y el Tarim ${ }^{11}$. En el período de crecida, para evitar inundaciones de ese distrito regado ${ }^{12}$ el agua fluía también a través del ramal septentrional, desaguando en las bajuras sudorientales (cfr. isohipsas de la figura 1b). El Kuqar, con un volumen mucho menor, no presentaba estos problemas, y su flujo era completamente absorbido por las zonas cultivadas.

De los canales principales, el agua pasa a los secundarios (arik) para finalizar en los terminales (korgach) desde los que se distribuye por el método de riego por inundación, a las parcelas de varios huertos. De la descripción de la situación de Khotan (Hedin 1900:20) extraemos algunas ideas interesantes, válidas también para el oasis de Kuqar. La gestión de un östäng que aprovisionaba los diversos núcleos de un asentamiento se sometía al control del mirab ${ }^{13}$, el cual, con la ayuda de los yüz baxi ${ }^{14}$ del área interesada, garantizaba la aplicación de la nauvatt, la ley del agua relativa a la cantidad y a la periodicidad del turno.

Marcadísimas eran, pese a este propósito, las variaciones estacionales. La nauvatt valía, de hecho sólo durante la primavera y el otoño, es decir, durante los períodos de escasez de agua. Sobre todo, la primavera representaba el momento de crisis: el ligero aumento de caudales ligado a las lluvias y a la fusión de las nieves en cotas bajas, debía ser repartida entre los campesinos de las diversas aldeas en un momento de elevada demanda ${ }^{15}$ y eso podía generar una distribución desigual (Schomberg, 1932:507) y tensiones de varios tipos $^{16}$. Para obviar la escasez primaveral, el agua otoñal se distribuía en los campos inundándolos, para saturar completamente el suelo, que se helaba durante el invierno y estaba así húmedo después del deshielo, cuando era trabajado ${ }^{17}$.

Durante el verano, en cambio, la llegada de la crecida (sil) hace innecesario el reparto, la distribución parsimoniosa creando más bien, como se ha visto, problemas de exceso de agua. En la estación de crecida, el comportamiento se desligaba de los acuerdos colectivos y cada cual hacia uso de un riego con elevados volúmenes de agua, mientras que la duración de los mismos y su frecuencia respondían sólo a la capacidad de gestión de la corriente de agua. Quizá, bajo esta luz se puede interpretar la acusación de «chapuceros» y la falta de organización de las prácticas de riego, que un observador inglés (Schomberg, 1932: 506) dirigía a los agricultores turcos; veremos también que la práctica del riego

11 Xayar, terraza del rey.

12 Dadas las direcciones de los cauces y su pendiente los desbordamientos se dan sobre todo en la orilla derecha. Aún en los años 80, Xayar (980 m sobre el nivel del mar) sufre las consecuencias de la rotura del dique $(983 \mathrm{~m})$ que la baña por el norte.

13 Mir-ab Señor del Agua es una palabra iraní: como otros términos relativos al riego, a la agricultura y a la alimentación (Karez, bostan, bagh y meidan — ver además han, pane, etc. — se remonta al sustrato indoeuropeo de estos oasis, que fueron integrados en el espacio turco sólo a partir del S. X D.C. (cfr. Stein, 1912).

14 Literalmente 100 hombres: indica el jefe de un núcleo de consistencia demográfica, por ello, de cien personas. Por asimilación jefe local de un kent o de parte de la aldea.

15 El calendario agrícola tenía y tiene en la primavera (abril-mayo) un período de elevada necesidad de agua: primer riego para el grano primaveral; segundo riego para el invernal; abundante riego para el maíz y el algodón. Se debe recordar que en Xayar se cultivaba exclusivamente grano primaveral (oasis del tipo single cropping spring-wheat: Chang Chi-Yi, 1949:64) mientras en Kuqar se practicaba también la siembra otoñal (Hedin, 1900:57): la mayor seguridad de un manto nivoso en el piedemonte y, en cambio, la mayor frecuencia de hielos tardíos en el sector inferior explican la diferencia.

16 Los turnos bastante largos (en el caso de Khotan se llega a 36 días) podían llevar al agotamiento de los recursos antes de completar el ciclo de turnos: los trechos inferiores de los canales podían ser duramente castigados (cfr. nota 9). Por lo que se refiere a este territorio, ya en los primeros años del S. XX se señalan problemas de falta de agua en Qimen, cerca de Xayar, ligados a la expansión de la superficie regada en la zona septentrional del oasis (Stein, 1912; vol. II:381).

17 Es un sistema aún adoptado en el Oasis de Kuqar, denominado riego del suelo helado (tong osa). 
estival respondía a un preciso criterio agroecológico. De todas formas, la construcción y la gestión de las infraestructuras de regadío, aún no estando enmarcada en organizaciones sociales de la escala y del nivel propio de las llamadas «asociaciones de regantes», respondía a acuerdos e implicaciones de trabajo social muy precisas. Así, los canales se excavaban colectivamente, y lo mismo sucedía en la construcción de diques y márgenes (Hedin, 1900: passim), mientras el derecho de acceso al agua estaba ligado a la cantidad de trabajo prestado por las familias ${ }^{18}$.

Por lo que se refiere a la organización espacial del regadío, ésta se ligaba a la topografía, hecho que aún se evidencia con claros signos en el paisaje actual (fig. 2). Los canales corren a lo largo de la nervadura de las digitaciones elevadas del cono, del que se abren las puertas para cada unidad, que se encuentran así, colocadas simétricamente sobre las dos vertientes del microrrelieve, según un gradiente altimétrico al que corresponde también una mutación de la morfología agraria y de los destinos de uso del agua.

En la parte alta, a lo largo de los canales protegidos por hileras de álamos y de olivos de Bohemia, se abren los patios (hayla) ${ }^{19}$, circundados por un jardín (bagh) de cultivos arbóreos (frutales, álamos y olivos de Bohemia) y hortícolas; más al exterior —y más bajo- sigue un área (etiz) de pequeños campos cultivados (máximo $2 \mathrm{mu}=1.300 \mathrm{~m}^{2}$, pero se desciende con frecuencia a verdaderos parterres de pocas decenas de metros cuadrados) también en régimen de cultivo mixto pero con predominio de cereales y algodón, circundados por una hilera (qidir=cortina) de álamos y jigde (olivos de Boehemia). Tal vez, según la anchura y la pendiente pueden ser terrazas (pälämbäy etiz). Estas dos secciones —bagh y etiz-componen el bagh baran, el cultivo perenne sobre «suelos de oasis» intensamente cultivado (fig. 2 punto a). Al exterior, en la sección inferior de la vertiente constituida por suelos chao-tu, se extiende el maydan (en persa plaza, extensión abierta) superficie amplia como un openfield, con un barbecho /kuzlek) que puede interesar al 50\% de la superficie total. Aquí se practican los cultivos más resistentes a la sal, que comienza a ser abundante, tales como: trigo, maíz, arroz, girasol, cáñamo. Finalmente, el fondo de la depresión, fuertemente salinizado y con suelos más compactos, se destina a pastizales (otlak), y en contadas ocasiones al cultivo del arroz.

Se evidencian claramente dos procedimientos para atenuar los efectos de las sales: el cultivo estratificado, con una fuerte cobertera arbórea, para modificar el clima local reduciendo la evaporación del suelo, y por otro lado, favoreciendo la transpiración; el cultivo de los terrenos más elevados, con mayores pendientes y menor presencia de sales, facilita la introducción de especies menos halófilas, ya que el nivel freático se encuentra a 3 ó 4 metros; de estos terrenos más elevados, el agua desciende por gravedad a zonas más bajas, donde además se acumulan las mayores cantidades de sales, con niveles freáticos situados a menos de un metro de profundidad, que ayudan a la aparición de un rico pastizal halófilo.

De esta manera, cada riego aporta una abundante cantidad de agua de lixiviación: ésta es la racionalidad agroecológica a la que habíamos aludido antes, esto es, la «sobreirrigación» condenada por Schomberg, que encuentra la manifestación más evidente en el ocasional cultivo del arroz en los sectores inferiores del maydan.

Junto a la fertilización animal y humana, y a los largos períodos de barbecho, en las

18 Para Kuqar se señala que el trabajo de un Kätman (la típica azada de hoja ancha de la región, utensilio versátil y adoptado a trabajos en suelos ligeros) es decir, el trabajo realizado por un hombre correspondía a un Kätman de agua con el que regar, es decir, la tierra que un hombre puede cultivar (Chang Chin-Yi, 1949:47).

19 Para esta reconstrucción, terminológica y estructural del cultivo uighur, debo mucho a la competencia y a la precisión de T. Hoppe, que sentidamente agradezco. 
partes centrales y en las periféricas al cultivo, estas prácticas constituían un sistema agroecológico que había sabido afrontar las limitaciones medioambientales (sobre estos aspectos Betke y Hoppe, 1987; Betke, Küchler y Obenauf, 1987).

La falta de cultivos perennes, propia de las bajuras, se convertía en una regla constante en el sector inferior del extenso cono y de la llanura aluvial del Tarim. El problema de las inundaciones estivales que afectaban a los amplios lechos de inundación, y la elevada salinidad de los suelos, procuraban mitigarse con fórmulas de producción y de hábitat completamente diferentes a los de la parte alta del cono. Estas fórmulas, que eran propias de las partes altas de la cuenca del Tarim, resultaban muy bien reflejadas en la organización productiva y territorial de las riberas terminales del gran río, conocidos como loplik (Hedin, 1900: passim). No existen asentamientos permanentes, pues éstos son estacionales, más o menos consolidados y localizados en las motas (dung, dong) para huir de la crecida, desde los cuales utilizan de modo diferenciado los nichos de un ecosistema extremadamente variable en el tiempo y en el espacio. Se dedican sobre todo, a la cría de ovejas y cabras aprovechando los pastizales ribereños, especialmente la Glycyrrhiza, especie muy abundante que era objeto de pastoreo estacional; la riqueza ganadera de Xayar era y es abundante, al igual que los cereales de invierno (trigo), practicados en las bajuras y en las orillas del lago, buscando la humedad aportada por las crecidas estivales (cultivos de décrue). Pero también era importante la recogida de madera para muebles o para combustible ${ }^{20}$, la pesca practicada bloqueando con las redes los afluentes de los ríos, la caza, y la recogida de raíces de Glycyrrhiza.

Las actividades tradicionales consistían por tanto, en una utilización de los recursos hídricos diversificada en el tiempo y en el espacio: agricultura de regadío en las zonas elevadas, y pastizal halófilo en las bajuras; regadío estacional ${ }^{21}$ y baja densidad de la ocupación del suelo, con amplias superficies en barbecho, mantenido con parte del agua aportada por las aguas de crecida, que alimenta las partes bajas del curso, permitiendo el mentenimiento de una biomasa que es aprovechada de múltiples formas, constituyendo al mismo tiempo un cinturón vegetal que protege del viento.

Se trataba de una utilización del ecosistema - laxa y flexible-, que garantizaba un alto grado de subsistencia para la población local (admitido también por un crítico de la agricultura tradicional como lo es Schomberg, 1932: 50), pero que, es necesario recordarlo, puede subsistir solamente en un contexto de baja densidad demográfica, ya que no prevé la maximización —espacial y temporal— del uso de los recursos con fines agrícolas.

\section{El sistema de riego con la intervención china}

«Terreno no utilizado, desperdiciado»: éste es el término con el que los chinos designan las bajuras ocupadas por los pastizales, cuya gestión — productiva y de conservación a un tiempo- es vital en la conservación del agroecosistema uighur. Una denominación ligada a las especifidades propias de la agricultura china, basada en cultivos continuos, en los que prevalece netamente el arado y la cría de ganado, queda relegada a una posición marginal, según una finalidad de maximización del rendimiento energético (Buchanam,

20 La madera para carpintería es, sobre todo, el tograkh ( $P$. difersifolia), mientras para combustible se utilizan las raíces leñosas del julgur (Tamarix sp).

21 La derivación gravitatoria es, de hecho, un método con elevada capacidad de corrección respecto al espacio, pero débil respecto al tiempo: el flujo se puede dirigir pero no puede ser acumulado (Durand Dastes, 1977:40). 
1970, Gourou, 1948). El pastizal, —así como el aprovechamiento forestal, la pesca y la agricultura de décrue - les pareció por tanto a los chinos — en los intentos de colonizar el Xinjiang a partir de 1949- como un espacio subutilizado, inadecuado por la modalidad empleada, para constribuir a la construcción de las bases económicas del estado revolucionario.

Era necesario aprovechar mejor el ecosistema para obtener los recursos que «los hermanos menores $»^{22}$ de las minorías necesitaban, desterrando un sistema de producción «semifeudal» poco productivo. El desarrollo de los recursos agrarios — agua y tierra- era un objetivo de los revolucionarios, concordante con el nuevo orden social que se estaba instaurando en todo el país, y como tal fue establecido.

El control del agua adquiere en este contexto un valor fundamental, convirtiéndose en el eje de la política territorial china, reflejando poco a poco sus caracteres, las modificaciones, y los objetivos.

\section{La evolución de la colonización}

Sobre todo en los primeros años — de 1949 a 1957—, fue el ojo del estratega el que guió la intervención. En Kuqar, como en toda la cuenca del Tarim, se persiguió más que un aumento de la producción, un cambio de la realidad social y productiva tradicional, de los sistemas agrarios, de la fuerte implantación islámica, de las relaciones de producción, con un intento de socavar las bases organizativas y productivas de una sociedad diferente y hostil. La reforma agraria y el control de los recursos de agua por parte de la Armada Popular de Liberación ${ }^{23}$, caracterizan a esta fase, en la que los chinos se preocupan sobre todo, por alejar los posibles riesgos de su presencia en la región ${ }^{24}$. Una fase pionera, en la cual se controla el agua para controlar el terreno (Belke, Küchler y Obenauy, 1987: 104; Betke y Hoppe, 1987: 9).

Un cambio radical, al igual que el que sobrevino en todo el territorio chino, se verificó al confirmarse las medidas productivistas del Gran Salto Adelante (1958-1960) durante el cual se exige a la nación la movilización general de los recursos — naturales y humanoscon el fin de potenciar la base productiva de la Revolución ${ }^{25}$. En las regiones secas del país, ello se tradujo en grandes campañas de colonización de tierras sin cultivar; los criterios adoptados fueron netamente inspirados, sobre todo, en estas regiones fronterizas y de nueva colonización, ya seguidas a fin de los años 30 en la Unión Soviética; son destacables, el poderoso desarrollo del regadío (grandes canales y numerosos embalses), la extensión masiva de bonificaciones (grandes parcelas de cultivo), y la creación de barreras arbóreas con el fin de proteger contra el viento, a los nuevos campos abiertos que sustituían a la agricultura tradicional mixta de los uighur, basada en la práctica de cultivos arbóreos y herbáceos.

Por lo que se refiere a Xinjiang, El Gran Salto y en general todo el $2^{\circ}$ Plan Quinquenal, debían dirigir el desarrollo de todo el piedemonte meridional del Tian Shan (Shabad,

22 Los Han se refieren a las minorías con el término didi (hermano menor): la aparente benevolencia de esta locución se debe interpretar a la luz del respeto y obediencia que, según el pensamiento confucionista, se debe al hermano mayor, justamente a los Han (Benson y Svanberg, 1988:61).

23 Sólo en 1978 el gobierno de las aguas de la región se transfirió a manos civiles, pasando a la competencia de las administraciones locales.

24 A diferencia de cuanto sucedió en la cuenca de Zungaria en la que las intervenciones tuvieron una finalidad netamente productiva, empezaron ya en el I Plan Quinquenal (1953-57) (Faggi, 1988).

25 Sobre este punto, y en general sobre la evolución políticoeconómica de la República Popular (Cfr. Colloti Pischel, 1980 y Etienne, 1976). 
1972), sobre el que se ejercía ya un adecuado control territorial.

En Kuqar destaca sobre todo, la construcción de embalses en el piedemonte y de canales de distribución ${ }^{26}$, que debían permitir el almacenamiento de las aguas del Ögän — las invernales no utilizadas y los excedentes del verano- para tener una mayor disponibilidad durante la primavera. Estas actuaciones, además de constituir una respuesta a la tradicional carestía de agua en la primavera, reflejaban las exigencias de la reconversión de cultivos, a las que también debía someterse el Oasis de Kuqar, que llevaron consigo la propagación del cultivo del algodón y del trigo de invierno, considerados como cultivos estratégicos para el mercado nacional — tomar los cereales como eje de la agricultura ${ }^{27}$.

Se procedió también a la colonización del tramo inferior del curso, mediante el establecimiento del Xiang Tarim (Fig. 1c) ${ }^{28}$ y la constitución de Unidades Colectivas de Cultivo, las cuales debían realizar también una sobresaliente labor de puesta en cultivo de tierras incultas difundiendo la agricultura de regadío mediante canales de derivación. Hay que decir, a este respecto, que durante el Gran Salto, la ganadería resultó bastante penalizada en favor de la agricultura: estas intervenciones, más que dirigirse al desarrollo del sector zootécnico, representaban una etapa de la vasta operación de demarcación y control del territorio uighur. La estructura fundamental de este proceso fue la colectivización de las bases sociales de la producción, por la cual, a partir de $1958^{29}$ todo el espacio rural del Tarim fue reconvertido según el modelo de las comunas y de las brigadas de producción. Simultáneamente, se implantó en la zona de transición entre el cono y la llanura aluvial, mediante algunas brigadas chinas de colonización, que debían funcionar como vectores de modernización y de desarrollo productivo ${ }^{30}$, aunque faltaron, en el Oasis de Kuqar, los potentes y programados asentamientos de los cuerpos de producción y de construcción del Xinjiang, que tanta importancia tuvieron en el Oasis de Aksu y de Korla ${ }^{31}$.

Las decisivas intervenciones de potenciamiento agrícola, se prolongaron en el Xinjiang

26 Se trata de los embalses Gran Salto (al SO de Kugar, de $7 \mathrm{Hm}^{3}$ de capacidad, hoy casi completamente aterrado), $1^{\circ}$ de Mayo (al N de Toksu, con capacidad de $46 \mathrm{Hm}^{3}$ ), y Cobiyin (al NO de Xayar, con capacidad para 4,5 $\mathrm{Hm}^{3}$ ), realizados en 1958 para almacenar las aguas del Ögän.

27 La presencia del agua en los embalses permite potenciar la oportunidad del riego de abril, fundamental para los buenos rendimientos de los dos cultivos. Durante el Gran Salto, se incrementó el cultivo del trigo de siembra otoñal también en la parte inferior del oasis que antes sólo conocía la siembra primaveral (cfr. nota 15) por lo que se refiere al rendimiento es, respecto a este último, teóricamente superior en un $30 \%$. Sin embargo, se ha comprobado después que las heladas tardías y la falta de nieve pueden crear graves problemas al cultivo invernal en esta zona.

28 Hoy residen cerca de 3.000 habitantes de los que 913 son han (llegaron en 1960-1962) que cultivan $25.000 \mathrm{mu}$, sobre todo de trigo y algodón.

29 En el otoño de 1959, la colectivización del pastoralismo de Xinjiang era basically complete (Benson y Svanberg, 1988:76).

30 Además de la brigada de Xiang Tarim (cfr. nota 28), se señalan 4 brigadas (2.000 habitantes) en Toybolldi, al sur de Xayar, instaladas en 1961 y además utilizadas también como campos de reeducación a través del trabajo para detenidos políticos chinos.

31 Los C.P.C. (Cuerpos de producción y de construcción) son grandes administraciones del Estado, basadas en el modelo del sovjos soviético (Trolliet, op cit.:38). Instituidos en 1954 como células operativas de las divisiones agrícolas del ejército popular de liberación, han realizado islas de población han, organizadas militarmente y de agricultura moderna con una discreta dotación tecnológica, en todas las regiones de nueva colonización de la periferia china (a finales de los años 50 había 2.500, con un total de 2,8 millones de adeptos exsoldados: Tregear, 1965:168). En el Xinjiang, los C.P.C. son 170, ligados a la desmovilización de la $2^{\mathrm{a}}$ y $6^{\mathrm{a}}$ armada, para un total aproximado de 1 millón de habitantes, y han tenido un papel decisivo sobre todo en la cuenca de Zungaria (140), mientras en la del Tarim (30) se han limitado a ocupar la llanura aluvial del gran río, en correspondencia con los oasis de Aksu y Korla y del sector terminal, en Tikanlik (Betke y Küchler, 1986; Kolb, 1986; Betke, Küchler y Obenauf, 1987). 
hasta los primeros años de la década de los 60 , favoreciendo por lo tanto una profunda reorganización del espacio rural y un aumento de las superficies agrarias. Al mismo tiempo, el empleo de una única modalidad de desarrollo, tanto aquí como en todo el país, la adopción de prácticas y metodologías de cultivo inadecuadas (reducción del barbecho ${ }^{32}$, penalización de la cría de ganado y de cultivos arbóreos, los monocultivos de trigo y algodón, etc.) generaron una situación de crisis ambiental y productiva ${ }^{33}$, con reacciones de descontento y resistencia por parte de la población uighur, que veía minadas las bases de su propia subsistencia (Betke, Küchler y Obenay, 1987:107, Erlach, 1988:59). Era, por lo tanto, necesaria una fase de consolidación y optimización, que fue posible por el período de reflexión pragmática que sufrió China en los inicios de la década de los 60, después de las agudas crisis agroalimentarias de los tres años difíciles.

En Kuqar, las expansiones agrícolas cesaron y fueron relanzadas la arboricultura y la cría de ganado asociado a oportunas rotaciones (difusión de la alfalfa) mientras se cuidaron la eficacia de las redes de riego, el drenaje y la construcción de setos que protegían contra el viento. Al igual que en el resto de China, se apuntó un aumento de la calidad más que de la cantidad de la superficie cultivada, recuperando algunos aspectos de la agricultura ecológica tradicional y racionalizando el sistema productivo: la agricultura no debía estar más al servicio de la industrialización, y representaría la base de un sistema económico en el que la industria era el factor de arrastre.

Con todo, en 1966 la revolución cultural puso fin a esta fase de reflexión, reintroduciendo una fuerte presión sobre los recursos, unida a un rechazo a la adopción tanto de las prácticas agroecológicas de la sabiduría uighur, como las prácticas agronómicas maduradas en los veinte años de intervención china. De todos modos, en Kuqar, como en todo el Xinjiang, el árbol y los animales fueron considerados como peligrosas concesiones a la agricultura tradicional, a la que fue contrapuesta la pureza del campo abierto y el monocultivo cerealícola ${ }^{34}$, según una rotación extremadamente simplificada de la que resultaba eliminada la alfalfa, elemento que aportaba al ciclo nitrógeno, cada vez más buscado en fertilizantes minerales y siempre menos en la ganadería.

El aumento de la salinización ha sido la consecuencia obvia, también por la expansión indiscriminada y anárquica de la superficie regada y, al mismo tiempo, el fervor ideológico que llevó a una redefinición de los espacios rurales: la geometría de los grandes campos se llevó también a las tierras uighur cultivadas desde antiguo ${ }^{35}$, mientras carreteras y canales fueron rectificados, reagrupándose también las viviendas geométricamente, con una drástica reducción de los asentamientos dispersos tradicionales. Es ésta, una práctica intensa y concentrada de transformación territorial, de la que sólo podemos imaginar su capacidad y modalidad según algunos testimonios, y que ha sustituido al mosaico de tablero de ajedrez (Betke y Hoppe, 1987).

Mientras tanto, en el cono del Ögän y en la llanura del Tarim destacaban otras potentes intervenciones hidráulicas, puntos fundamentales de la gran obra de puesta en cultivo de áreas que parecían, a ojos de los chinos aún inutilizadas. En la segunda mitad de los años

32 La superficie en barbecho ha descendido del 30 al 10\% del total (Xie Xiangfang, 1990).

33 En particular, se trata de una intensa deforestación, y de una salinización ligada a la expansión del regadío en las tierras deprimidas y de una aridificación edáfica debida a las prácticas agronómicas. Sobre estos temas (Cfr. Zhu Zhenda y Liu Shu, 1983; Chen Hua, 1984; Hoppe, 1987). En general, para una exposición muy crítica de los problemas ambientales ligados a la política de desarrollo acelerado del Gran Salto, cfr. Smil, 1983.

34 Ha habido destacadas operaciones sistemáticas de abastecimiento de árboles en los bagh baran de los uighur.

35 Es un ejemplo la aldea de Beleges, en el Xiang de Üqkat (Xian de Toksun) en la que el cultivo uighur ha sido reagrupado en grandes campos abiertos de más de $500 \mathrm{mu}$. 
sesenta se inicia la construcción de algunos embalses de retención en la zona meridional del oasis, que se enmarcan en esta lógica, permitiendo el incremento del regadío en el Xian de Xayar $^{36}$. Crecen también los asentamientos en la llanura del Tarim, sobre todo por obra de los chinos, a los que compete el empeño de movilización revolucionaria ${ }^{37}$ y que pasan por primera vez al sur del río ${ }^{38}$. El éxito de la fuerte difusión del regadío no tarda en hacerse sentir, con agudos y difundidos fenómenos de salinización en la parte inferior del cono y en la orilla izquierda del Tarim.

El fin del maoísmo, el fracaso de la banda de los cuatro y la reafirmación de las reformas denghiste lleva, a partir de 1978, a una profunda crítica de la irracionalidad económica de la política agraria. Tras una primera fase, en la que se busca aumentar la producción mediante un sistema de incentivos, anulando la política de bajos precios agrícolas que había favorecido a la ciudad y a la industria, se llega en 1984 a las grandes reformas: fin del sistema de colectivización y nacimiento del Gobierno Local, liberalización del mercado ${ }^{39}$, introducción del sistema chenbao o de responsabilidad con el cual los medios de produción (tierra, agua, animales, empresas industriales no estratégicas) son confiadas a sujetos privados. Éstos asumen la responsabilidad de la producción con contratos de largo vencimiento, a veces transmisibles por herencia, teniendo la libertad de comerciar de forma privada el excedente de la cuota impuesta y conferida. Es una fase de racionalización productiva, de mejoras técnicas, de aumento de la productividad, que adquiere apariencias particulares en el Xinjiang, en el marco de la política de desarrollo puesta en marcha en 1983 con el lema aprovechar el gran noroeste (Hoppe, 1987:67).

Y seguramente eso se refleja en las intervenciones agronómicas ${ }^{40}$ e hidráulicas efectuadas en Kuqar: se intenta racionalizar el sistema de riegos del oasis, mediante una planifica-

36 Se trata de los embalses de Paman (al sureste de Xayar, $47 \mathrm{Hm}^{3}$ ), Geranlik (al SO de Xayar, era llamado Antiimperialismo y es el de mayor capacidad con $68 \mathrm{Hm}^{3}$ ), Antirrevisionismo (en Qimen, alimenta los campos de trabajo) y Akköl (pocos $\mathrm{Hm}^{3}$ al sur del Tarim). Estos embalses, alimentados por las aguas del Tarim, aprovechan desniveles mínimos de la llanura aluvial (2-3 m) y se conectan al río a través de largos canales de riego. Hay dos fases de llenado (después del 20 de julio la más importante y de diciembre a marzo, con una cantidad que depende de la intensidad del deshielo) y dos de desembalse (para el riego otoñal del trigo, y para la primaveral del algodón y trigo).

37 Indicativa es la llegada en 1968 de algunos centenares de han a un asentamiento uighur preexistente del Tarim Xiang, para constituir la Brigada Unida Tarim, unos cuarenta kilómetros al este de Xayar.

38 Son tres brigadas han (2.000 personas) las que, en 1975, con ocasión de la realización del embalse de Akköl, se asientan en los territorios de pastos al sur del Tarim, tradicionalmente usados por los uighur de Toyboldi (estación zootécnica $\mathrm{n}^{\circ}$ 1), introduciendo un monocultivo algodonero de algunos millares de mu. Este asentamiento ha dado origen a agudos problemas de degradación ambiental, entre los que se señala la devastación de las praderas de Glycyrrhiza para aprovechar las raíces, lo que provoca la reacción de los pastores uighur, para los que la planta representa un óptimo forraje tardoestival y otoñal. A los chinos se añaden algunos centenares de uighur, obligados a realizar establos permanentes de cría de ganado en estas áreas de precedente pastoreo transhumante.

39 Lo que, como se ha visto, no excluye que aún hoy hayan cuotas de producción obligatoria de cultivos estratégicos, que deben ser conferidos al estado a precios regulados: en Kuqar, se trata de algodón y cereales (trigo y maíz) de los que el estado comercializa respectivamente el 100 y el $25 \%$

40 Una demostración de esta nueva sensibilidad ambiental se puede ver en algunas iniciativas para la protección del manto vegetal que, si bien con dificultad, son cumplidas. Oficialmente, se limitan tanto las extracciones de raíz de regaliz como el corte de toghrak: una rápida visita a las orillas del Tarim permite observar inmediatamente la nominalidad de estas medidas, especialmente en las zonas al sur del río.

41 En este marco se inserta la constitución de la Autoridad del Ögän (Weigan-he livyu guanlichu) que se ocupa de la gestión de los recursos hídricos y de su distribución en los diversos Xian, y que depende del Departamento de las Aguas (Shuili chu) del Dique de Aksu. A su vez, Xian y Xiang son dotados de su propio Departamento de las Aguas. 
ción integrada de recursos ${ }^{41}$, la realización —ex novo o mediante mejora- de modernos canales de enlace entre los distintos sectores regados ${ }^{42}$ y el desarrollo de la extracción de aguas subterráneas. Pero sobre todo, se afronta el agudo problema de la eficacia de la red de riego, que se mantiene en niveles bastante bajos: si los adatos oficiales hablan del 0,37\% (Weigar-he..., 1987) ${ }^{43}$ en realidad la relación entre volúmenes hídricos y superficie agrícola ofrece resultados más ordinarios (Tab. 1), con valores que se acercan a los oficiales sólo para las mejores áreas de Kuqar, y que se alejan enormemente - aunque sea obvio- a medida que se deciende al sur.

Es un problema básico, ligado a la evaporación de los amplios y poco profundos embalses $^{44} y$, sobre todo, a la infiltración, que repercute en la extensión de las tierras regadas y en la difusión de la salinización a causa del ascenso del nivel freático.

Hoy se apunta por lo tanto, un aumento de la eficacia de riego, con mejoras de los cauces naturales, impermeabilización de canales ${ }^{45}$ y reforzamiento de los diques de embalses $^{46}$; se crea una red de desagüe para hacer descender el nivel freático y disminuir el problema de la salinización ${ }^{47}$; se intenta en fin, difundir las modalidades de riego ${ }^{48}$ y políticas de precios del agua que conlleven una mayor economía del gasto ${ }^{49}$, fijando los valores de referencia para cada cultivo.

Y sin embargo, a pesar de la prioridad dada a la intensificación, no faltan algunos procesos de expansión de cultivos, los cuales, aunque limitados, dan una idea de que la tendencia no está completamente agotada. Se observan aún nuevas colonizaciones de las

42 Se trata de los canales Estrella Roja $\left(45 \mathrm{~m}^{3} / \mathrm{s}\right.$, y $\left.50 \mathrm{~km}\right)$ y Gran Salto $\left(25 \mathrm{~m}^{3} / \mathrm{s}\right.$ y $\left.11 \mathrm{~km}\right)$ que llevan agua del Ögän hasta el Xian de Kuqar; del canal Xin-xa (xinhe/toksu-xayar) $\left(90 \mathrm{~m}^{3} / \mathrm{s}\right.$ ) del cual se destacan en un primer momento los numerosos ramales que llevan a los Xiang de Xinhe y después a lo largo del canal Xayar, hacia el Xian homónimo $\left(45 \mathrm{~m}^{3} / \mathrm{s}\right.$, y $\left.22 \mathrm{~km}\right)$. El eje de todo el sistema es la gran obra de Kum Tura, en el ápice del cono, que con un sistema de compuertas llega a laminar crecidas superiores a $400 \mathrm{~m}^{3} / \mathrm{s}$, vertiendo los excedentes de la capacidad total de los canales $\left(160-170 \mathrm{~m}^{3} / \mathrm{s}\right)$ en los dos cauces naturales del río.

43 Según las directrices del gobierno del Xinjiang, cada mu debería tener una dotación en la fuente de 700$900 \mathrm{~m}^{3} / \mathrm{mu} / \mathrm{año}$, para un volumen efectivo final de $300 \mathrm{~m}^{3}$, con una eficacia, por tanto, entre el 30 y el $43 \%$ (Weigan-he...,1987); en realidad, la autoridad del Ögän, considerando las pérdidas en el campo debidas a las modalidades y a la sobreabundancia de riego, tiende a suministrar $400 \mathrm{~m}^{3} / \mathrm{mu} / \mathrm{año}$, valor sobre el cual se ha calculado la eficacia en la tabla $\mathrm{n}^{\circ} 2$.

44 Las pérdidas por evaporación pueden legar al 30\% del total de agua embalsada.

45 Para los canales principales, se valora una pérdida por infiltración del 1-2\% cada kilómetro. La impermeabilización de los canales con láminas de PVC o mediante el empedrado, es actualmente la preocupación fundamental de la Autoridad y de los diversos Departamentos de Aguas; hoy en día se ha realizado para sólo 14 $\mathrm{km}$ de los $200 \mathrm{~km}$ de los canales de primer órden. Se calcula que, completando la operación para toda la red de primer y segundo orden $(700 \mathrm{~km})$ se obtendría un ahorro del $15 \%$ con el que se podrían regar $240.000 \mathrm{mu}$. Obviamente los costes de intervención son bastante elevados, cercanos a los 85 millones de yuan. La suma destinada por las autoridades a la impermeabilización de canales durante el período 1986-1990 se acerca a 41,6 millones de yuan, el 49\% del plan total de inversiones (Weigan-he..., 1987).

46 En particular se han potenciado los del embalse $1^{\circ}$ de mayo $(2,5$ millones de yuan $)$ que, a menudo dañados por las fuertes olas formadas por la incidencia de los vientos catabáticos, dejan filtrar el agua aumentando la salinización en territorios circundantes.

47 Se están finalizando más de $80 \mathrm{~km}$ de red drenante principal $\left(1,5 \mathrm{~m}^{3} / \mathrm{s}\right)$ sobre todo en la parte meridional del cono, con un gasto total, en el quinquenio 1986-1990 de 3 millones de yuan (Weigan-he...,1987). Aún se carece sin embargo, de redes de canales secundarios.

48 Sobre todo, una buena nivelación de parcelas y la reducción de sus dimensiones (hasta 1 mu: ¡era la dimensión típica de la agricultura tradicional uighur!).

49 Actualmente el agua es pagada por los campesinos según la superficie que riegan, independientemente del consumo: de 1,5 a 2,5 yuan/mu, a los que se añaden los costes de manutención, comprendidos entre 1,5 y 7 yuan por mu en la zona meridional. Se está, sin embargo, pasando (oficialmente debería haberse hecho en 1988) a un precio volumétrico, con descuentos progresivos con el aumento del ahorro realizado respecto a los volúmenes de referencia (Tab. 3) (Weigan-he..., 1987). 
TABLA 1

SUPERFICIE CULTIVADA, VOLÚMENES HÍDRICOS Y EFICACIA DE RIEGO

\begin{tabular}{|c|c|c|c|c|c|c|}
\hline XIAN & $\begin{array}{l}\text { S.A.U. por } \\
1.000 \mathrm{MU}\end{array}$ & & $\begin{array}{r}\text { VOLUME } \\
\text { En } \mathbf{H m}^{3}\end{array}$ & & $\begin{array}{l}\text { VOLUMEN } \\
\text { en } \mathbf{m}^{3} / \mathbf{m u}\end{array}$ & EFICACIA \\
\hline \multirow{5}{*}{ Kuqar } & 984 & & 1.206 & & 1.226 & $32,6 \%$ \\
\hline & de los que & 665 & 816 & Ögän & 1.227 & $32,6 \%$ \\
\hline & & 281 & $\begin{array}{r}300 \\
30\end{array}$ & $\begin{array}{l}\text { Kuqar } \\
\text { pozos }\end{array}$ & 1.117 & $35,5 \%$ \\
\hline & & 20 & 40 & Tarim & & \\
\hline & & 17 & 20 & torrentes & & \\
\hline \multicolumn{7}{|l|}{ Toksun/ } \\
\hline \multirow[t]{2}{*}{ Xinhe } & 420 & & 561 & & 1.335 & $29,9 \%$ \\
\hline & & & $\begin{array}{r}548 \\
13\end{array}$ & $\begin{array}{l}\text { Ögän } \\
\text { pozos }\end{array}$ & & \\
\hline \multirow[t]{3}{*}{ Xayar } & 510 & & 943 & & 1.843 & $21,6 \%$ \\
\hline & de los que & 360 & $\begin{array}{r}636 \\
7\end{array}$ & $\begin{array}{l}\text { Ögän } \\
\text { pozos }\end{array}$ & 1.786 & $22,4 \%$ \\
\hline & & 150 & 300 & Tarim & 2.000 & $20 \%$ \\
\hline \multicolumn{7}{|l|}{ Total } \\
\hline Oasis & 1.914 & & 2.710 & & 1.416 & $28,2 \%$ \\
\hline Baikeng & 750 & & 900 & Ögän & 1.200 & $33,3 \%$ \\
\hline
\end{tabular}
1989.

FuENTE: Elaboración a partir de datos de las autoridades del Ögän y de las oficinas de economía de los Xian.

TABLA 2

VOLÚMENES MEDIOS (M³/MU) Y PERÍODOS DE RIEGO POR CULTIVOS

\begin{tabular}{|c|c|c|c|c|c|c|}
\hline CULTIVO & $\begin{array}{l}\text { ANTES DE } \\
\text { SIEMBRA }\end{array}$ & $1^{\mathrm{a}}$ & $2^{\mathrm{a}}$ & $3^{\mathrm{a}}$ & $4^{\mathrm{a}}$ & TOTAL \\
\hline Trigo & 90 & 15 oct & 5 abril & 20 abril & 15 mayo & \\
\hline Invernal & $5-20$ set & 20 nov & 20 abril & 5 mayo & 15 junio & 300 \\
\hline Trigo & 100 & 20 abril & 1 mayo & 18 mayo & 7 junio & \\
\hline \multirow[t]{2}{*}{ Primavera } & $11-20 \mathrm{mar}$ & 5 mayo & 25 mayo & 4 junio & 20 junio & 300 \\
\hline & 100 & 20 mayo & 15 junio & 5 julio & 15 junio & \\
\hline \multirow[t]{2}{*}{ Maíz } & 25 marzo & 20 junio & 5 julio & 25 julio & 10 agosto & \\
\hline & $\begin{array}{l}15 \text { abril } \\
70\end{array}$ & & & & & 350 \\
\hline \multirow{5}{*}{$\begin{array}{l}\text { Maíz de } \\
\text { ciclo } \\
\text { breve } \\
\text { Algodón }\end{array}$} & de 30 juni & 10 agosto & 25 agosto & & & \\
\hline & a 25 julio & 20 agosto & 20 setiem & & & 220 \\
\hline & 100 & & & & & \\
\hline & de 15 marz & 20 mayo & 10 junio & 25 junio & 1 agosto & \\
\hline & a 10 abril & 5 junio & 20 junio & 11 julio & 30 agosto & 380 \\
\hline
\end{tabular}

FuENTE: Weigan-he..., 1987. 
partes distales del cono y en la llanura del Tarim, realizadas ya sea a través de una planificación del trabajo colectivo ${ }^{50}$, o bien a través de la iniciativa individual protagonizada por squaters ${ }^{51}$, mientras se asiste por doquier, en las bajuras entre las digitaciones del cono, a una erosión del otlak por parte de cultivos en expansión; nuevos canales de regadío están en vías de realización, sobre todo hacia el suroeste (Xiang Tarim).

Pero es sobre todo una gran obra, el dique de Kizil, en construcción sobre el Ögän en la cuenca de Benqeng (Fig. 1 b) la que polariza atenciones y espectativas: sobre ella se apunta para resolver, a un tiempo, las exigencias de expansión y de racionalización de la superficie regada ${ }^{52}$. La misma permitirá solucionar el problema hidráulico de Kuqar: el almacenamiento de la abundante agua de verano, con protección ante posible crecidas, utilizándola en la primavera. Respecto a los embalses de la llanura, éstos presentan la ventaja de una capacidad muy superior, con pérdidas menores debido a la menor ETP y por tratarse de suelos más compactos, contando además con una posición estratégica sobre todo el oasis, ya sea por lo que se refiere a la capacidad de prevención de avenidas como por las posibilidades de riego.

A propósito de ello, se habla de un aumento general de las disponibilidades de agua para todo el oasis durante la primavera, y de una expansión importante de la superficie regada — unos $150.000 \mathrm{mu}$ — hacia el suroeste en el Xian de Kuqar y Xayan ${ }^{53}$. En realidad, sólo una colonización de esta entidad requiere con la eficacia actual de los suelos de la parte distal del oasis, más de $420 \mathrm{Hm}^{3}$ al año, el $135 \%$ de la capacidad útil del embalse. Aún considerando la doble estacionalidad de recarga ${ }^{54}$ parece quedar bien poco para el aumento de las disponibilidades hídricas en los terrenos ya cultivadas ${ }^{55}$. Se impone, entonces, un aumento general de la eficacia, con los problemas financieros ya recordados, y con la exigencia de adoptar métodos de ahorro de los volúmenes de agua aplicados: el dique, como todas las grandes obras hidráulicas, es visto como el catalizador para realizar un plan más general de modernización de la estructura agraria y territorial.

La historia de la intervención hidráulica china registra, por lo tanto, una oscilación continua entre fases de expansión y fases de intensificación. Expansión en el tiempo y en

50 Durante nuestra estancia se estaba realizando, al SE de Üzün en el Xian de Kuqar, en terrenos bajos y salinos, una bonificación de más de 4.000 mu mediante el trabajo a corvée (yiwu-laodong de 12 a 45 días por cabeza al año) de habitantes de 13 aldeas, los cuales a cambio tendrán cinco años de exención de tasas agrícolas. Otro ejemplo lo constituye la estación de pastoreo al este de Xayar a lo largo del Tarim: desde 1980 se han cultivado $20.000 \mathrm{mu}$, con un proyecto total de bonificación de 100.000, con una notable vocación forrajera (bovinos yili para carne). Actualmente se utilizan las aguas del Tarim, pero está programado un canal para recibir las aguas del Ögän.

51 Fenómenos de este tipo están presentes sobre todo, en Toyboldi, en el área ocupada por grandes campos de trabajo (Cfr. nota 30) donde se permite la posibilidad de colonizaciones privadas que resultan, sin embargo, un completo riesgo para el trabajador, puesto que no incluyen en las tierras un aprovisionamiento hídrico al menos oficialmente asegurado.

52 La presa, financiada por el Banco Mundial con 600 millones de yuan debería haber sido completada en 1990. Esto formará una cuenca artificial que recubrirá $10.000 \mathrm{mu}$ (capacidad total 607, capacidad útil 320, reserva muerta $130 \mathrm{Hm}^{3}$, con una profundidad media de unos cincuenta metros.

53 Se trata de un aumento del $12 \%$ de la superficie agraria útil total. La rentabilidad de la obra estaría asegurada destinándose al algodón más de la mitad de la superficie. Japón ha ofrecido una financiación para la realización de una fábrica algodonera.

54 La recarga de embalses se produce en verano, con las aguas de crecida, salvo aperturas de compuertas con ocasión de las breves crecidas del Kizil Su, para dejar fluir las aguas con elevada carga sólida. Un segundo llenado se verifica en invierno, con las escasas aguas no utilizadas, que pueden reintegrar ese $50-60 \%$ de la capacidad que ha sido utilizado en el riego antes de la siembra del trigo. En total, se pueden calcular 480-500 $\mathrm{Hm}^{3}$ de almacenamiento al año.

55 Los funcionarios del Xian de Xayar lamentan a propósito de ésto, el retraso en la realización de los canales de riego a la parte inferior del oasis ya cultivada. 
el espacio a través de los embalses situados en los piedemontes, lo que permite anticiparse a la siembra (algodón) y se incrementan los rendimientos (trigo), aliviando la crisis hídrica primaveral, a través de nuevos canales con los que se amplía la superficie cultivada. El Gran Salto Adelante y la revolución cultural han sido los dos momentos decisivos de esta expansión, que ha aumentado una superficie cultivada que ha pasado de $1.200 .000 \mathrm{mu}$ en 1949 a los casi 2.000 .000 en 1989, y que ha sextuplicado la producción cerealícola; que ha abordado al oasis de Kuqar con algunos millares de han y, sobre todo, con un proceso de chinización del territorio uighur, que ha introducido, en fin, en el agrosistema del oasis, junto al aumento de la productividad, nuevos vínculos y nuevos problemas.

La intensificación, ligada a una racionalización productiva de las prácticas agrícolas y a una redefinición de ciertos objetivos abstractamente fijados durante las fases expansivas debido a la aparición de nuevos problemas, lo que ha conllevado un revisión pragmática de las ideas de los primeros años 60.

De hecho, a la búsqueda de una mayor eficacia de riego y a la realización de las redes drenantes, se añaden la expansión de los cultivos en las depresiones y en la llanura aluvial, así como los nuevos asentamientos en el tokay; mientras que los distintos planteamientos parecen encontrar un punto de soldadura ideal en la realización del dique del Kizil, la gran obra que debería permitir realizar el control completo sobre las aguas y sobre el espacio del oasis.

Pero hay otro profundo nivel de transformación: la expansión de la superficie regada y el aumento de la demanda social de agua imponen el paso a un uso más parsimonioso de los recursos hídricos, a su integración en un ámbito de competencias más vasto y al mismo tiempo más detallado. En el control unitario ejercido por el nuevo dique, en las nuevas modalidades de minimización del gasto de agua por unidad de superficie, se está observando una nueva escasez de agua que está incidiendo en la configuración territorial del oasis. El coste del riego, pasando de la unidad de superficie a la de volumen, traduce dicha transformación, transfiriendo a la praxis de la agricultura una nueva lógica reproductiva en la que el hermano mayor han representa el elemento innovador.

\section{La articulación territorial de la colonización}

A pesar de la tentativa de normalización y de homogeneización natural en las etapas de grandes expansiones apenas recordadas, la colonización china del Oasis de Kuqar se ha articulado según los módulos espaciales determinados por las preexistencias territoriales. Es definible, a este respecto, una lógica territorial que ha interpretado y afrontado de modo específico las diversas zonas del oasis, dando lugar a una verdadera y propia geografía de la colonización. Una intervención diferenciada, por lo tanto, a tenor de los caracteres físicos, de las modalidades de territorialización precedentes, de las finalidades por las cuales el singular ámbito espacial era encuadrado en la estrategia general. Podemos así reconocer tres modalidades de colonización aplicadas a otros tantos módulos territoriales de la realidad preexistente, cada una caracterizada por criterios, finalidades y problemas específicos.

\section{Reestructuración de las áreas de antiguo asentamiento y de agricultura consolidada}

Es la intervención primaria que ha actuado sobre las áreas tradicionales de la agricultura uighur, es decir, las zonas septentrionales del oasis y los ejes elevados de las digitacio- 
nes del cono, organizadas según el modelo bag baran. Ambitos de antigua y densa colonización, no han sido objeto de expansión agrícola ni de inmigraciones, sino más bien de intensificaciones y reestructuraciones. En este sentido, han vivido las fases iniciales de la lucha en las sociedades retraídas y semifeudales, con la remoción de la propiedad y de las estructuras agrarias tradicionales y con la sucesiva reorganización colectivista (pueblos y brigadas de producción).

Las transformaciones del paisaje rural han sido intensas, sobre todo por lo que se refiere al habitat, que ha sido reagrupado o alineado a lo largo de canales y carreteras, y por lo que se refiere a la morfología agraria, que ha conocido la eliminación de los cultivos arbóreos ${ }^{56}$ y la introducción de los grandes campos abiertos ligados a las prácticas colectivas de cultivo: un decidido proceso de geometrización que ha tenido los momentos de mayor intensidad durante el Gran Salto y la Revolución Cultural, y que resulta destacado por el empleo de altas hileras de álamos contra el viento que delimitan las grandes parcelas. También los canales, de todos los niveles, han sido rectificados para aumentar la velocidad de deslizamiento y reducir las pérdidas.

Las prácticas de cultivo han conocido profundos cambios, sobre todo por las variaciones de escala y por la obligación de agrupar los cultivos en grandes áreas homogéneas, que requieren una nueva y más coordinada organización del trabajo; bastante más complejo resulta, respecto a las precedentes párcelas minúsculas, el trabajo de nivelación, esencial para garantizar la eficacia del riego por inundación; coordinadas y sincronizadas han de ser las obras de cultivo; inéditos los problemas que conlleva el drenaje de parcelas de tan enormes dimensiones. Se está también verificando una progresiva mineralización de los suelos, por la reducción de la práctica del barbecho y por el disminuido aporte de estiércol, debido a la contracción de los pastos locales y a la consecuente concentración de los animales, que incluso aumentan en las zonas de pasto especializado de la montaña o de la sección inferior del cono ${ }^{57}$.

Desde el punto de vista hidráulico, las intervenciones han consistido en la rectificación de los canales y en su impermeabilización, con el fin de garantizar un aporte hídrico en las secciones del valle y de reducir, junto a la infiltración, los problemas de salinidad. Aunque en medida limitada, éstas empiezan de hecho a hacerse sentir en esta zona que tradicionalmente no las conocía, sobre todo en las márgenes de embalses (Gran Salto, $1^{\circ}$ de Mayo, Cobiyin). Resulta bastante relevante, a este propósito, la dimensión de las parcelas y el aumento de la evaporación que se registra tras la desaparición de cultivos arbóreos, mientras que obviamente, no es extraño el paso de la utilización de abonos orgánicos a minerales.

Las mayores disponibilidades de agua y la relativamente elevada productividad agrícola, los pone hoy en primera línea para el paso a la nueva contabilización volumétrica de los costes de riego: algodón y frutales son, en este sentido, particularmente requeridos por cuanto que permiten una renta bastante elevada respecto del consumo de agua. La ciudad y la carretera aproximan esta zona al mercado, de forma que comienzan a nacer los agricultores de 10.000 yuan, los nuevos ricos ligados a las reformas agrarias denguistas. No debe maravillar, por lo tanto, que aquí se encuentren también las primeras aplicaciones del actual redescubrimiento de las técnicas tradicionales relativas a las dimensiones de las

56 En estas zonas se ven a veces, en medio de grandes campos, espléndidas moreras o albaricoques aislados, que han logrado escapar de las talas, significando un testimonio del modelo agrario tradicional.

57 La tradicional transhumancia, que interesaba sobre todo el Xian de Kuqar, se está transformando cada vez más en ganadería de montaña (en verano a más de $3.000 \mathrm{~m}$ sobre el nivel del mar, y en invierno alrededor de los 1.500-2.000 m) por obra de los pastores uighur y kirghisi, justo por la contracción de las áreas de pastoreo de llanuras, de ésto se deriva una sobrecarga de los pastos alpinos y una elevada mortalidad a final de invierno. 
parcelas, al redescubrimiento del árbol, a una rotación sagaz que reintegra las leguminosas, a una búsqueda de nuevas formas de cultivo mixto. Embriones de este paradójico paisaje nuevo-antiguo, despuntan aquí y allá, sobre todo bajo la forma de parcelas de frutales combinadas con hortalizas, algodón y maíz, junto a los que los bovinos, quizá de raza Ili o Alatan, consumen piensos ensilados de reciente difusión.

\section{Densificación de cultivos y asentamiento de las llanuras, antes dedicadas al pasto}

La intervención en cuestión, es la progresiva erosión por parte del asentamiento, o por parte de los cultivos - del otlak-, la extensión del pasto localizada en llanuras alargadas entre las digitaciones del cono, que se extiende, alargándose, a las secciones meridionales, donde el cono se difumina en la llanura aluvial del Tarim.

Un ámbito de protección, como se ha visto, por cuanto que permitía la evacuación en condiciones de seguridad de la sal de las áreas cultivadas dominantes, y en cualquier modo, también su remoción por medio del pastoreo de especies halófilas, pero también un ámbito productivo importante para la gandería, y no menos importante para la agricultura, por cuanto ponía a disposición del bagh baran el estiércol, importante para el mantenimiento de los suelos de oasis. Para los chinos, un espacio inutilizado, en el que se debían expandir los cultivos.

En estas depresiones que atraviesan de norte a sur todo el oasis, pero que adquieren mayor importancia y dimensión en la zona central y meridional, a medida que los relieves pierden entidad, se ha registrado un progresivo avance de los cultivos, ya sea bajo la forma de grandes colonizaciones ligadas a nuevos canales, ya como descanso de los cultivos del adyacente cultivo abierto y temporal (maydan), que continúan, como se ha visto, aún hoy (cfr. Fig. 2, los puntos c). Se ha venido configurando una trama de cultivos discontinua y desmembrada en la cual, con los cultivos que han tenido éxito, alternan otras parcelas abandonadas por el exceso de humedad y salinidad, una trama rociada de caseríos aislados, en los cuales los afloramientos salinos corroen las paredes en breve tiempo. Es raro el árbol, lo que confiere a estos paisajes una marcada connotación de diversidad. Únicos signos estables y duraderos, los canales rectilíneos de riego que descienden del norte, a los cuales hacen de contrapunto, cada vez más frecuentemente desde hace algunos años, los de drenaje que descienden hacia el Tarim.

La salinidad, agravada por la pesadez de los suelos, representa el principal problema agronómico, debido también al ascenso del nivel freático (Fig. 1.b), cuya salinidad aumenta hacia el $\operatorname{sur}^{58}$ : el cultivo de arroz es practicado de tanto en tanto, para lavar los suelos. Una atención particular se presta a este respecto a las lluvias que activan la salinización, particularmente peligrosa para el algodón, porque realizan un riego no muy profundo y percolante. Se hace entonces necesario un trabajo superficial del terreno, para anular la capilaridad, o incluso un riego inmediato y abundante: después de las lluvias de inicios de verano, estas llanuras bajas se animan en trabajo. Otra práctica de cultivos onerosos está ligada al aterramiento de canales de riego: la débil pendiente de las áreas deprimidas favorece la sedimentación, de modo que se debe proceder a la limpieza de los canales, que se realiza dos veces al año en régimen de corvée $e^{59}$.

La acrecentada demanda de tierra y las directivas estatales están, por lo tanto, corroyen-

58 La salinidad de la capa más superficial es del 1,5\%. en el sector meridional del cono.

59 En mayo, porque lo favorece el flujo de crecida, y en invierno antes del deflujo primaveral de los embalses. Esta generación se hace menos irretrasable, obviamente, en la parte septentrional del cono, de mayor pendiente. 
do estos espacios de pastoreo, transformando el significado de sus caracteres: la sal, útil y preciada antaño, hoy se ha convertido en un problema; la compacidad de los suelos arcillosos, óptima para la producción forrajera hace pesado el trabajo y difícil el drenaje. Al mismo tiempo, estas tierras, situadas en las partes distales de los canales, tienen un aporte hídrico precario, que además no es seguro para el futuro, como se ha visto, en el caso de las colonizaciones individuales ${ }^{60}$. Entre las tierras altas ocupadas por cultivos tradicionales, y las grandes roturaciones de la zona meridional, los espacios de densificación, no gozan ni de las ventajas ambientales o de la madura organización agrícola de aquéllos, ni de la atención del aparato público que compete a estos últimos.

\section{La frontera agrícola en el tokay}

Justamente aquí, en el rico ecosistema del bosque de ribera y ripícola, verificamos hoy las intervenciones más fuertes y evidentes. Estamos en la parte inferior del oasis, tradicionalmente utilizada con modalidades flexibles y laxas que se inscribían en el territorio con signos difuminados: los asentamientos estacionales en las barrancas, los recorridos de pasto y de abrevamiento del ganado, las coronas del corte del tograkh, el cultivo de las depresiones que la crecida del Tarim rítmicamente borraba cada año. Espacios vacíos que, por lo tanto, los chinos han intentado llenar. Nuevas expansiones agrícolas, creación de centros estables de cría de ganado, también inmigración han, como hemos visto, aunque en medida contenida. Una intervención masiva, iniciada con retraso respecto a las de zonas superiores del oasis: iniciada durante el Gran Salto ha tenido su apogeo máximo durante la Revolución Cultural, llegando sin embargo con menor intensidad a nuestros días. Si en los dos modelos precedentes se ha modificado o ampliado el espacio agrícola preexistente, en este caso se está produciendo uno completamente nuevo, con una territorialización que se imprime con nitidez en el ambiente. Después de kilómetros de bosques aparecen de golpe grandes campos rectangulares, las nuevas obras hidráulicas, los habitats ordenados y rectangulares, concentrados en torno a los centros de servicios técnicos y de organización política. La red viaria es, sin embargo, en conjunto aún bastante precaria, de modo que estos asentamientos constituyen casi islas, sobre todo si se trata de colonias chinas: es la lógica del tun tien, la guarnición militar autosuficiente que surge en los primeros siglos de la presencia han en la región ${ }^{61}$. Una lógica que, por otro lado, frente a las nuevas instancias productivas, parece cambiar a favor de una mayor integración comercial ${ }^{62}$. Desde el punto de vista del cultivo, se ha creado un ecosistema agrícola completamente nuevo, aunque se ha procedido de forma bastante expeditiva, empujados por la voluntad de expander las bases de la revolución: escogidos los terrenos, normalmente sobre terrazas de la llanura aluvial, son deforestados y aplanados, aportándoles después el agua del Tarim, pero también del Ögän, a través de largos canales, que tal vez han aprovechado canales abandona-

60 Para estas áreas está creciendo, en las partes meridionales de los Xian de Toksu y Kuqar, el uso de bombas eléctricas para alumbrar agua subterránea, que todavía presenta los inconvenientes de la salinidad, de la menor temperatura y de la falta de fertilización que ofrecen los limos. La realización de pozos coresponde a los Departamentos de Aguas, y las aguas son suministradas al mismo precio que las superficiales.

61 A continuación de la Liberación de los años 80, algunos de los uighur asentados al sur del Tarim, durante la Revolución Cultural volvieron a su lugar de origen (Toyboldi): la colonización transfluvial se está convirtiendo, sobre todo, en una cuestión china.

62 Está en proyecto, a nivel estatal, una carretera que unirá Hotän, en la orilla sur del Takla Makan, con Aral y Xayar, en torno a la cual trazar un eje de desarrollo destinado a explotar los ingentes recursos de petróleo y algodón de la llanura del Tarim; en esta realización se incluye la mejora de la vía que une Xayar al Xiang Tarim. 
dos y que, en cambio, al atravesar las llanuras bajas quedaron colgados. Importante, desde el punto de vista hidráulico, la realización de grandes embalses en las llanuras, mediante largos diques de tierra en torno a depresiones naturales. Nuevas son también, las prácticas de cultivos forrajeros y la siega de los prados, que se acompañan de la afirmación de una ganadería estable. Se debe señalar una discreta dotación de maquinaria pesada, adecuada a este modelo de gran colonización, que resulta necesaria en algunas fases del cultivo, por la textura arcillosa del suelo. Se registra una fuerte orientación hacia cultivos industriales: oleaginosas y, sobre todo, algodón, que aquí reporta productividades elevadas por las altas temperaturas estivales, si bien se presenta tal vez el peligro de heladas tardías ${ }^{63}$.

Profundas transformaciones ambientales han seguido a la colonización. Las más evidentes se refieren a la cobertera vegetal: a las roturaciones se asocian la tala del bosque para leña, que sigue con una banda de algunos centenares de metros, todas las pistas rurales, así como en las llanuras se buscan las raíces de Glycyrrhiza. El conjunto sigue, no obstante, las recientes tentativas de limitación. Otras modificaciones, menos espectaculares pero aún más relevantes, se refieren a la hidrología. En las terrazas roturadas, en las más antiguas y elevadas se ha registrado una sensible elevación del nivel freático local (Fig. 1. b) sobre todo a lo largo de los canales colgados y en las cercanías de cultivos, con agudos problemas de saturación y salinización de los suelos. Al contrario, en el gran lecho de inundación donde se encuentra la zona más rica del tokay (Petrov, 1962:148) se señala un descenso del nivel freático: las aguas del Ögän son aprovechadas sólo con las mayores crecidas, mientras el curso sinuoso del Tarim, reducido a bien poco durante la primavera y el otoño, a finales del verano y en el invierno produce inundaciones de entidad bastante menor que las registradas antes de la colonización, por las cuantiosas distracciones de caudal en el piedemonte ${ }^{64}$. El bosque de ribera se resiente, con una progresiva contracción y un empobrecimiento de la cobertera. Las perspectivas son preocupantes: el nuevo dique de Kizil reducirá con mucho el aporte del Ögän, llegando a almacenar el agua de las inundaciones estivales, distribuyéndolas en los $\operatorname{campos}^{65}$; la mayor eficacia de riego, aún aumentando los volúmenes hídricos para los cultivos, reducirá la infiltración y por lo tanto, los aportes subsuperficiales en las faldas del Tarim, con lo que las redes drenantes descargarán en el río agua fuertemente salinizada.

El nuevo territorio de la llanura aluvial, avanzadilla han en la tierra de los uighur, mantenido y deseado por el gobierno central, está pagando los efectos de un modelo productivo cuya sostenibilidad, desde el punto de vista ambiental parece cuanto menos, precaria.

\section{Conclusiones}

Idealmente, pero también por la fuerza de las acciones emprendidas, detrás de la nueva

63 Para reducir el efecto del frío primaveral, se han difundido desde hace algunos años, las cubiertas de PVC, que todavía inciden notablemente en los costes de producción (40 yuan/mu sobre cerca de 150 totales) provocando que los agricultores dependan de la financiación del Banco Agrícola en el caso de que se malogre la cosecha.

64 En la estación de Konaqimän, las crecidas estivales del Tarim son del orden de $500-600 \mathrm{~m}^{3} / \mathrm{s}$, mientras en los años 50 se superaban regularmente los 1.000. Hay que tener presente que una intensa bonificación ha afectado tanto a los oasis alimentados por los tres ríos que forman el Tarim (Yäkänd, Hotän, Aksu) como a la región de Aral, inmediatamente en el valle de confluencia, donde se han puesto en cultivo más de 40.000 ha.

65 Para el Xiang Tarim, se prevee una disminución del 30\% de pastos regados. 
territorialización del Oasis de Kuqar, hay mil millones de chinos. Chinos con el peso y la presión de su multitud, con una enorme demanda de recursos, de bienes y de desarrollo, con su cultura, su concepción de la agricultura, del territorio, y del mundo.

En realidad, los uighur no son completamente extraños a esta lógica. Atacados por una avidez de tierra cuya intensidad crece con el incremento demográfico, halagados por las perspectivas de la agricultura comercial ${ }^{66}$, también ellos abrazan con adhesión creciente las nuevas modalidades, mientras los representantes de las minorías étnicas presentes en los órganos de gobierno local se muestran, si es posible, más chinos que los chinos a este respecto.

Si bien con las dificultades y los problemas que cualquier transformación de una estructura rural comporta, también ellos han emprendido la vía de la intensificación y de la especialización: el sistema de cultivo tradicional, lo hemos visto, se podía regir por otro lado, sólo desde la perspectiva de una limitada demanda social de recursos, en el marco de una exigua densidad demográfica ${ }^{67}$. Sin embargo, frente a los caracteres de una intervención ya pluridecenal y frente a la generalidad de sus efectos, algunas reservas y resistencias se han abierto camino; algunas críticas están emergiendo; algunas correcciones de rumbo se han impuesto en la propia estrategia de colonización china. Las intervenciones realizadas, pero también las resistencias y las revisiones se vierten en un último análisis de la práctica hidráulica, que como hemos visto, está vehiculando la nueva geografía del oasis.

Las líneas fundamentales de la lógica hidráulica parecen emerger bastante claras del examen hasta aquí efectuado. Frente a los volúmenes hídricos que durante el verano y el invierno descendían al Tarim para desperdiciarse en el desierto, frente a las inmensas extensiones de terreno no cultivado que circundan la exigua extensión regada, la lógica de la expansión y de la intensificación del uso de los recursos era una elección obvia, de cualquier forma obligada. Por lo tanto, se ha intentado extender lo máximo posible la distribución de las aguas en los terrenos aluviales y retener el exceso de las aguas de crecida para desembalsarlas en momentos de escasez: los ingentes caudales que escurrían en los cauces, han sido laminados y distribuidos en una densa red de canales, que ya recubren gran parte del cono. El flujo superficial ha sido por tanto, ralentizado y dispersado, con un notable incremento de la superficie regada, pero también con una contracción de los volúmenes superficiales tributarios del Tarim y con un aumento considerable de la infiltración y la evaporación, que han llevado a la elevación del nivel freático y a la acentuación de fenómenos de salinización, sobre todo en la parte centro-meridional del oasis. El aumento de la eficacia de la red de riego y la construcción de una red drenante ha sido, por tanto, el paso siguiente para obviar estos problemas: se intenta de este modo, por un lado, tener una mayor disponibilidad de agua para expander ulteriormente los cultivos, y del otro, establecer el nivel freático a una profundidad segura. Actuando así, sin embargo, se incrementa todavía la evaporación de las superficies cultivadas, reduciendo el aflujo de agua dulce al Tarim, que recibe, no obstante, proporcionalmente más cantidades de agua de infiltración, de elevada salinidad. En el intervalo, las capacidades de este mismo río son utilizadas de forma creciente por la puesta en cultivo de las terrazas aluviales, sobre las cuales trigo y algodón reemplazan el ecosistema del tokay. Paradójicamente, el gran dique

66 Justo el grado con el que las minorías étnicas llegarían a hacer propio el intenso desarrollo económico que está afectando a China parece ser una de las condiciones de la integración de las regiones occidentales al proyecto de construcción estatal (Cannon, 1989).

67 La población total del oasis ha pasado de 253.400 habitantes en 1950, a los 605.600 (90,8\% uighur) de 1988 (Xie Xiangfang, 1990). 
de Kizil y el aumento de la eficacia de los canales acentuarán estos problemas, laminando ulteriormente las crecidas.

¿Qué consideraciones se pueden extraer de este tipo de intervención, depués de haber recordado que la misma ha aumentado indudablemente la producción, y que por tanto ha contribuido a satisfacer la demanda primaria de desarrollo del Estado Chino?

Por lo que se refiere al Oasis de Kuqar, podemos decir que la intensificación ha pasado a través de la simplificación y la especialización del agroecosistema. En particular, se pueden señalar la reducción o la desaparición de dos elementos propios de la utilización del suelo, pero también se puede hablar de la cultura de los uighur, es decir, del árbol y la ganadería. El árbol es una protección contra el viento y la salinidad, pero también sombra, combustible para el riguroso invierno, fruta, con una destacada contribución a la dieta, y en fin, denominador común de cada mazar; el animal es alimento para los días de fiesta, moneda en los intercambios sociales, rédito que pasa a través de la comercialización, abono para conservar la fertilidad de los suelos de oasis. Ya han sido recordados los malhumores y las reacciones provocadas por las fases de mayor empuje para su eliminación; aquí se puede añadir que estos puntos principales de la realidad, productiva pero también social y simbólica, de los UIGHUR reemergen — y quizá nunca hayan desaparecido- en la organización del espacio doméstico, también en las recentísimas casas ligadas a la reorganización de asentamientos del máximo fervor de la Revolución Cultural, que son inmediatamente circundadas por altas barreras de álamos y que se protegen bajo los emparrados de vid y las frondas de frutales. Es decir, se recupera a otra escala lo que se ha impedido en el espacio público; el modelo es miniaturizado pero preservado, y por tanto no se puede evitar que reemerja y que, con ello, la simplificación vuelva a discutirse en el marco de un cierto retorno a algunas prácticas tradicionales, cosa, por otro lado, como se ha dicho de la que ya se han producido los primeros avisos.

Pero aquí entra en juego otra dimensión del problema. La misma lógica de la intervención se ha replicado de hecho, por todas las cuencas que alimentan el Tarim (los módulos hidráulicos de la ruta de la seda ${ }^{68}$ y ha provocado gravosas repercusiones en el nivel freático y sobre el régimen del Río Grande, con efectos ambientales (progresiva degradación del bosque de ribera, salinización, movilización de arenas) que suscitan ya preocupación incluso entre investigadores chinos (Zhu Zhenda y Liu Shu, 1983; Chen Hua, 1984) y que no son ya afrontables en el espacio de cada oasis. El cambio de la práctica hidráulica, con todo, ha cambiado drásticamente la escala de los problemas, haciendo ya necesario un plan de cuenca, una perspectiva integrada de todo el sistema hidráulico del Tarim ${ }^{69}$. Se trata, obviamente, de un salto enorme, a través del cual pasan los nuevos mecanismos de producción, el futuro de las relaciones entre grupos étnicos y el nuevo control del territorio. Un plan de este tipo tiene un valor económico, social y geográfico extremadamente relevante, por cuanto implica en elecciones decisivas y estratégicas en los diversos usos del suelo y en prácticas territoriales. ¿Quién redactará el plan? ¿Qué ventajas y qué desventajas tendrá sobre el territorio y sobre los grupos étnicos que lo habitan? Y hay en fin, que preguntarse cuál sería la sostenibilidad del aumento de rentas obtenido, dado el impacto ambiental que implica. Es una consideración que surge de inmediato frente a los problemas hidro-edáficos de la nueva agricultura y

68 El mismo proceso ha sucedido también en los módulos de la orilla suroriental de la cuenca del Tarim; por ejemplo, para el Keriya, cfr. Jäkel y Zhu Zhenda, 1991.

69 A nivel del gobierno del Xinjiang existe, desde 1989, un Comité para la Planificación de las Areas Fluviales, encargado de la gestión integrada de las aguas superficiales de la Región. Para el Tarim en particular, cfr. Xie Xiangfang y Mao Baodi, 1989. 
que resulta ineludible frente a la progresiva erosión del tokay: ¿cuánto rinden los nuevos cultivos obtenidos en el sector deforestado, si tras pocos años la sal hace ya su aparición, si la arena y el limo cubren los canales y sobre todo aterran embalses de retención de las aguas; cuánto valen la pérdida de las actividades tradicionales asociados al bosque de ribera; cuánto cuestan las medidas de protección que se deben emprender a escala regional frente a la aridificación provocada por la crisis del pasillo verde del Tarim? Pero quizá hay más aún: ¿qué valor le damos a la progresiva reducción del tokay, un ecosistema que, como nos recuerda J. Dresch (1982:146), en Asia ha sido completamente transformado en terreno cultivado, y que, por dimensiones y por endemismo de las especies implicadas representa a lo largo del Tarim una realidad única y relevantísima a nivel planetario, pero también en drástica reducción?

Estas problemáticas, que son productivas, sociales y territoriales, tienen aún en la cuestión hidráulica el sector privilegiado. Son problemáticas en torno a las cuales se interesarán las futuras relaciones entre han y uighur, entre las instancias de la modernización y del desarrollo, y las de la búsqueda de autonomía en el fondo del panturquismo. En cualquier caso, son problemáticas que también nos interesan a nosotros.

\section{Bibliografía}

BENSON, L. y SVANBERG, I.: The Kazaks of China-Essays on an Ethnic Minority, Uppsala, «Studia Multiethnica Upsaliensia», 5, 1988.

BETKE, D. y HOPPE, T.: «Mosaik und Schachbrett. Veranderungen der Agrarianlandchaft», Das Neue China, 1 (1987), pp. 8-11.

BETKE, D. y KÜCHLER, J.: «Erschliessung zentralasiatischer Trockengebiete Chinas», Praxis Geographie, 10 (1986), pp. 43-7.

BETKE, D.; KÜCHLER, J. y OBENAUF, K. P.: Wuding und Manas ökologische und sozioökonomische Aspekte von Boden und Wasserschutz in den Trockengebieten der VR China, Kassel, Gesamthochschulbibl., «Urba et Regio», 43, 1987.

BUCHANAN, K.: The Transformation of the Chinese Earth, London, Bell and Sons, 1970.

CAGNAT, R. y JAN, M.: Le Milieu des Empires. Entre Chine, URSS et Islam le destin de l'Asie Centrale, Paris, Laffont, 1981.

CANNON, T.: «National minorities and the internal frontier», in: GOODMAN, D. S. G. (a cura), China's Regional Development, London-New York, Routledge, 1989, pp. 164-79.

CHANG CHIH-YI: «Land Utilization and Settlement possibilities in Sinkiang», The Geogr. Rev., 39 (1949), pp. 57-75.

CHEN HUA: «Versandung und Oasen» (trad. ted. commentata da T. HOPPE), in: FAHRENHORST, B.; HOPPE, T. y ALBRECHT, D.: Umweltpolitik und Landnutzungsprobleme in der Volksrepublik China und Landern der Dritten Welt, «Landschaftsentw. u. Umweltforsch.», Berlin, T.U.B., 21, 1984, pp. 110-48.

COLOTTI PISCHEL, E.: «Repubblica Popolare Cinese», in: ID. (a cura), Storia dell'Asia, «Il mondo contemporaneo», Laterza, 1980, vol. III, pp. 124-54.

CUI XIAOLIN: Eco-environmental, Evolution in Tarim Valley and Countermeasures for its Control and Improvement, Urümqi, dattil., 1992.

DRESCH, J.: Géographie des régions arides, Paris, PUF, 1982.

DURAND-DASTES, F.: Systémes d'utilisation de l'eau dans le monde, Paris, SEDES, 1977.

ERLACH, S.: «Die Umweltverträglichkeit der Neulanderschliessung am Tarim-Oberlauf/region Aksu-Aral», in: KÜCHLER, J. y POHLMANN, G. (a cura), Landwirtschaft und Umwelt in den Trockengebieten der V.R. China, «Berl. Geowiss. Abhandl», Reihe C, 8, 1988, pp. 56-76.

ETIENNE, G.: La lunga marcia dell'economia cinese, Milano, Ed. Comunitá, 1976.

FAGGI, P.: «Colonizzaziones, ambiente e territorio nello Xinjiang (Asia centrale cinese)», 
Geogr. nelle Scuole, 33 (1988), pp. 347-59.

GENTELLE, P.: La Chine, Paris, PUF, 1974.

GLADNEY, D. C.: «Constructing a contemporary Uighur. National Identity: Transnationalism, Islamicization, and State Representation», Cah. d'Et. sur la Médit. Orient. et le Monde Turco-Iranien, 13 (1992), pp. 165-84.

GOUROU, P.: «La civilisation du végétal», Indonesie, 1 (1948), pp. 385-96 (ried. in Rev. Belge de Géogr, 93 (1969), pp. 225-36).

GRUSCHKE, A.: Neulanderschliessung in Trockengebieten der Volksrepublik China und ihre Bedeutung für die Nahrungsversorgung der chinesischen Bevölkerung, Hamburg, «Mitt. d.Inst. f. Asienkunde Hamb.», 194, 1991.

HEDIN, S.: Die Geographisch-wissenschaftlichen Ergebnisse meiner Reisen in Zentralasien 1894-1897, «Peterm. Mitteil Erg. H.»131, 1900.

HOPPE, T.: «An Essay on Reproduction: The example of Xinjiang Uigur Autonomus Region», in: GLAESER, B. (a cura), Learning from China? Environment and development in Third World Countries, London, Allen and Unwin, 1987, pp. 56-84.

— «Die chinesische Position in Oste-Turkestan/Xinjiang», China aktuell, (1992), pp. 358-65. JÄKEL, D. y ZHU ZHENDA (a cura), Reports on the 1986 Sino-German Kunlun Shan Taklimakan-Expedition organized by The Institute of Desert Research, Academia Sinica (IDRAS), Lanzhou and the Institute of Physical Geography of the Free University of Berlin, «Die Erde Erg.H.», 6, 1991.

KOLB, A.: «Xinjiang als Naturraum und ökologisches Porblemgebiet», Geoökodinamik, 7 (1986), pp. 29-40.

LATTIMORE, O.: La frontiera. Popoli e Imperialismi alla frontiera tra Cina e Russia (trad. ital.), Torino, Einaudi, 1970.

Map of the Chinese Turkistan and Kansu, from surveys made during the explorations of Sir Aurel Stein (Scala 1:500.000), General Survey of India, 1918-1922. Serial n. 17 «Kuga».

MECKELEIN, W.: «Zu physischer Geographie und agraren Nutzungsproblem in den innerasiatischen Wüsten Chinas», Geoökodynamik, 7 (1986), pp. 1-28.

PETROV, M.: «Typers de déserts de l'Asie Centrale», Ann. de Géogr., 71 (1962), pp. 131-55.

RECLUS, E.: Nouvelle Géographie Universelle-Vol.VII: «L'Asie Orientale», Paris, Hachette, 1982.

SCHOMBERG, R. C. F.: «The Climatic Conditions of the Tarim Basin», The Geogr.Jour., 75 (1930 a), pp. 313-20.

— «Three Journeys in the Tien Shan», The Geogr. Jour., 76 (1930b), pp. 25-38.

— «The Habitability of Chinese Turkestan», The Geogr. Jour., 80 (1932), pp. 505-511.

SHABAD, T.: China's Changing Map: National and Regional Development, London, Methuen, 1972.

SHI YAFENG; WANG ZONGTAI; LIU CHAOHAI y YANG ZHENNIANG: «Glacial Resources of the Arid Regions in Northwest China and Their Utilization», in: XINJIANG BRANCH, CHIN. ACAD. OF SCIENCES: Utilization and Development of Natural Resources in Arid and Semi-arid Lands, Beijing, Science Press, 1989, pp. 1-9.

SMIL,V.: «Deforestation in China», Ambio, 12 (1983), pp. 226-31.

STEIN, M. A.: Ruins of Desert Cathay. Personal narrative of explorations in Central Asia and Westernmost China, London, MacMillan, 1912, 2 vol.

TIAN YUZHAO: «Tokay on the delta at the lower reach of the Keriya River- a natural vegetation complex reflecting ecological degradation», in JÄKEL, D. y ZHU ZHENDA (a cura), op. cit., pp. 99-112.

TREGEAR, T. R.: A Geography of China, London, Univ. of London Press, 1965.

TROLlIET, P.: La Chine et son économie, Paris, Colin, 1981.

UNESCO: Carte de la répartition mondiale des régions arides, «Notes Techniques du MAB» 7, Paris, 1977.

WEIGAN-HE LIUYU GUANLICHU / AUTORITA'DELL'ÖGÄN: Rapporto sulla distribuziones dell'acqua durante il $7^{\circ}$ Piano Quinquennale nell'area di irrigaziones del fiume Ögän, sottoposto al Dipartimento delle Acque del Diqu di Aksu (in cin.), Kuqar, 1987. 
XIN XIANGAFANG: Hauptmerkale und Entwicklugstendenz der Oasenwirtschaft im Gebiet von Kuga-Xayar am nördlichen Rand des Tarimbeckens (trad. ted. di T. HOPPER), Urümqi, 1990 (dattil.).

XIN XIANGAFANG y MAO BAODI: «The Development and Management of the Tarim River», in XINJIANG BRANCH, CHIN ACAD. OF SCIENCES: Utilization and Development of Natural Resources in Arid and Semi-arid Lands, Beijing, Science Press, 1989, pp. 26-32.

ZHOU YUCHAO: «Water Resouces in Xinjiang and Their Evaluation», in XINJIANG BRANCH, CHIN ACAD. OF SCIENCES: Utilization and Development of Natural Resources in Arid and Semi-arid Lands, Beijing, Science Press, 1989, pp. 20-25.

ZHU ZHENDA y LIU SHU: Combating Desertification in Arid and Semiarid Zones in China, Lanzhou, Inst. of Desert Res., Academia Sinica, 1983. 